\title{
黒雲母の $\mathrm{Ti}$ 端 成分組 成 柳井地域領家変成岩類中 の黒雲母の $\mathrm{Ti}$ 置換 —-
}

$T i$ endmember composition of biotite Ti substitution in biotite from Ryoke metamorphic rocks in the Yanai district -

池田髄 (Takeshi Ikeda)*

\begin{abstract}
The chemical composition of Ti-poor and -rich biotites from Ryoke metamorphic rocks in the Yanai district are described by the substitution, $2 \mathrm{Ti}+\mathrm{C}^{\mathrm{V}}=2 \mathrm{~A} \mathrm{l}^{\mathrm{V}}+\mathrm{R}^{2+}$. By applying this stbstitu. tion to eastonite, a new endmember of $\mathrm{Ti}$-biotite, $\mathrm{K}_{2} \square \mathrm{R}^{2+}{ }_{3} \mathrm{Ti}_{2} \mathrm{Si}_{4} \mathrm{Al}_{4} \mathrm{O}_{30}(\mathrm{OH})_{4}$, is defined. The compositional space defined by phlogopite-talc-eastonite-muscovite and this Ti-biotite can express the composition of $\mathrm{Ti}$-bearing biotite better than other definitions of $\mathrm{Ti}$-biotite endmember.
\end{abstract}

\section{I.はじめに}

変成岩中の黑零母にTiが含をれることは広く知ら れている。黑雲母の Ti含有量と变成度, 黑零母の Fe/ $(\mathrm{Fe}+\mathrm{Mg})$ 比，欧びSi 含有量との関係は，Guidotti (1984)によって方々られている。それによると，1） T浛有量仕变成度の上年に伴なって高くなる。2）闌 に変成度でる $\mathrm{Fe} /(\mathrm{Fe}+\mathrm{Mg})$ 比の高い黒雲母の $\mathrm{Ti}$ 含 有量格，低いるの含有量上り高い。3）黑雲母のTi とSi角の相関がみられる。これらの性質汇最近の研 究でる支持されている(例えば, Pattison, 1987; Holdaway et al., 1988)。

固溶体の組成を极うに悕成分を決るると便利で市 る、个省若した黑零母の端成分を決めるために，黑 震母中のTiの増加はどの元素の增減を伴ならか存険

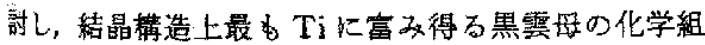
成老端成分之する。しかし，そのよらにして求めた端

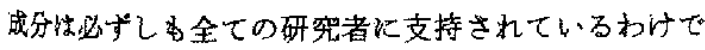

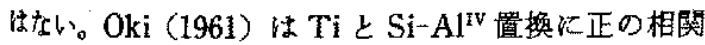
が台らること加ら Tiの增加は $\mathrm{Al}^{\mathrm{Y}}$ のそれを伴な

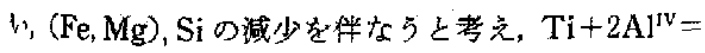

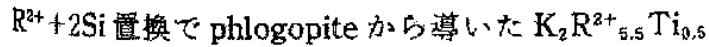

$\mathrm{Si}_{5} \mathrm{Al}_{3} \mathrm{O}_{20}(\mathrm{OH})_{4}$ 老端成分とした(但し, $\mathrm{R}^{2+}=\mathrm{Fe}+$ $\mathrm{Mg}+\mathrm{Mn}$ \%。Guidotti et al. (1977) 同し傾向を確認 しているが，端成分の提案性行なわなかった。Pattison (1987) 同じく( $\mathrm{Al}+\mathrm{Ti})$ と $\mathrm{Si}$ の急の相関を記載し ている。一方，Holdaway et al. (1988) は 6 配位元素 の総数と Ti との負の相関から八面体サイトの空席を 含む， $\mathrm{Ti}+\square^{\mathrm{vI}}=2(\mathrm{Fe}, \mathrm{Mg})$ の犆换かi $\mathrm{Ti}$ 考慮した黒 零舟の端成分を導く上考光, phlogopite汇この置換を 施した $\mathrm{K}_{2} \square_{2} \mathrm{R}^{2+}{ }_{2} \mathrm{Ti}_{2} \mathrm{Si}_{6} \mathrm{Al}_{2} \mathrm{O}_{20}(\mathrm{OH})_{4}$ 这端成分として 提案した。この端成分はDymek (1983)がグリーンラ ンド西部のグラニュライト相の広い組成範再の岩石

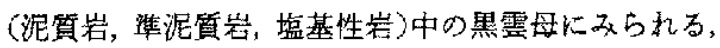
Tiの增加江伴な5最主主要な㯰換から求めた端成分 である。このょらにてiの增加に伴なって文られる元

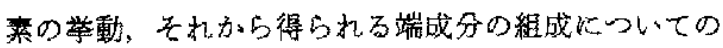
研究者間での不一致は，Guidotti (1984)が指摘するよ

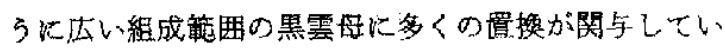
るたると考光台九る。固溶体心組成を記述するために

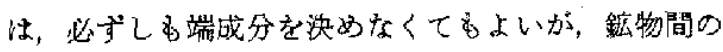
化学反応を报らに性端成分を定義した方が便利であ る。この端成分の組成の指定は結晶化学的河可能な範 国で任意であるが，その端成分で表現される組成空間
- 景都大学理学部地質学鉱物学教室 厂 606 京都南左京区北白川追分町
(平成 2 年 5 月 28 日受讨

平成 2 年 6 月 18 日受理） 
の中に全ての天然の黑雲母が含まれることが必要な条 件でる。

現在，著者が山口県柳井地域で研究している項家変 成岩類の黑雲母には，従来から提案されている端成分 を用いては適切江表現できないものが存在する。そこ

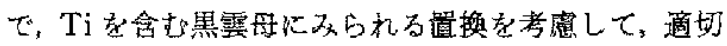
と思われる端成分について考察する。

\section{II. 黒雲母の組成}

筆者の研究対象は，山口県楖井地域仪分布する領家 变成岩類の濯質岩，及び珪質岩である。この地域は泥

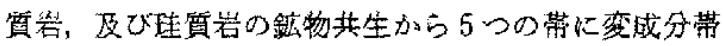
されている。即ち，緑泥石带，緑泥石一黒需母带，黑

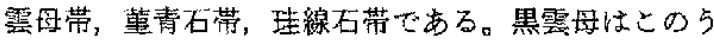
ら緑泥石带を除く全ての带に広く出現する。黑雲母の 分析には京都大学理学部のメネルギー分散型 $\mathrm{X}$ 線分析 蔆置（日立 S550+Kevex $8000 \mu$ )を用いた。今回分析 した全ての試料には石墨が含まれ，その多くにイルメ

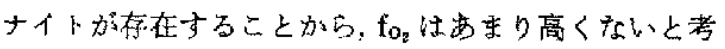

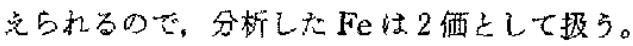

得られた黒雲舟の分析の Ti 含有量克薄片ごとに变 成度の低い力加ら並べて Fig. 1 亿示竞。变威度の上年

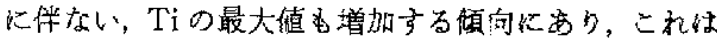
従来の記載汇調和的である(例壳ば，Guidotti；1984)。

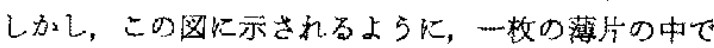
む Ti含有量火大きな変動の見られるすのがある。

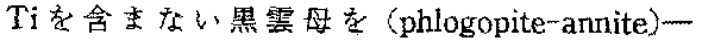
(eastonite-siderophyllite) - muscovite $55 つ の$ 端 成分で表示すると，Tiを含む黒雲母恃上記の端成分で 表現される空間に，Ti含有量に相当する Ti-biotite 端 成分を加充て表現される。Tiは四面体サイトに入ると

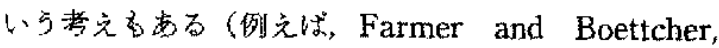
1981)。吏た, Whitney and McLelland (1983) の記 載した $\mathrm{TiO}_{2}=9.5 \mathrm{wt} \%$ とい5黑零母标, 四面体け1卜

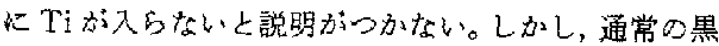
雲母ではたと夫Tiの一部方四面体サイトに入ってい るとしても，その量の見積もりは困難であり，多分あ

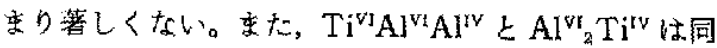
し化学組成であるので分析値だけでは Tiが，どのサ イトに入っているか決められない。

柳井地域の領家変成岩類の黑零母の組成を記述する ために，まず従来から提案されている端成分を用いて 放る。前述したよ5K, Oki (1961), Dymek (1983)及 び Holdaway et al. (1988) が端成分を提案している。 Oki（1961)は4 配位元素と6配位元素の浱度を記述与
るために4つの端成分を用いている；

$$
\begin{aligned}
& \text { Ti-biotite } \cdots \cdots \cdots \cdots \cdot \mathrm{K}_{z} \mathrm{R}^{2+}{ }_{5.5} \mathrm{Ti}_{0.5} \mathrm{Si}_{5} \mathrm{Al}_{8} \mathrm{O}_{20}(\mathrm{OH})_{4} \\
& \text { Phlogopite } \cdots \cdots \cdots \cdots \cdot \mathrm{K}_{2} \mathrm{R}^{2+}{ }_{8} \mathrm{Si}_{6} \mathrm{Al}_{2} \mathrm{O}_{20}(\mathrm{OH})_{4} \\
& \text { Eastonite } \cdots \cdots \cdots \cdots \cdots \mathrm{K}_{2} \mathrm{R}^{2+}{ }_{5} \mathrm{AlSi}_{5} \mathrm{Al}_{8} \mathrm{O}_{20}(\mathrm{OH})_{4} \\
& \text { Muscovite } \cdots \cdots \cdots \cdots \cdot \mathrm{K}_{2}[]_{2} \mathrm{Al}_{4} \mathrm{Si}_{5} \mathrm{Al}_{2} \mathrm{O}_{20}(\mathrm{OH})_{4}
\end{aligned}
$$

Oki (1961) の暲算法では，過鄱のTiはルチルをして 漖玩されて扰り，多量のTiを含む組成の定量的な表 現ができない。そのため， $\mathrm{TiO}_{2}=3 \mathrm{wt} \%$ 以上の黑雲时 の表現がしばしば困難である。

一方, Holdaway et al. (1988) の端成分は，A イトの空席と考虑して,

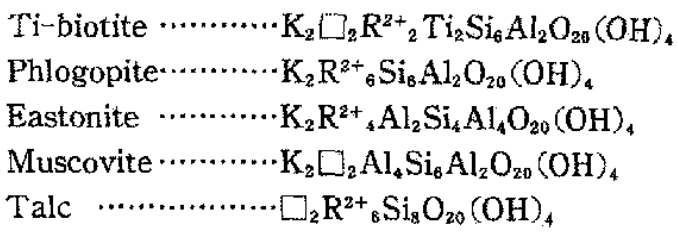

Q5 つを含んでいる (Holdaway et al. (1988)は, Babiotite として举げているが，Ba恃锺量であるので今回の議 論には用いない。また, wonesite 成分は phlogopite成 分として扱 5)。Dymek (1983)は上記の 5 つ $\mathrm{Ke}^{\mathrm{a+}-}$ biotite 老加六大空間党用いている。この空間て性，A サイトが 2 を越点, talc 成分が負になるものを除くと，

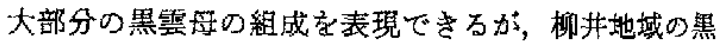
雲母の組成の一部，及び Guidotti et al. $(1975,1977)$ の記載した Applachian 帯, Maine 地域の黒雲母の組 成の一部は, muscovite 成分が負の値をむつ。

Oki（1961)の端成分が黒雲母の組成学適切纪表現で きない原图しして, phlogopite 加らの eastonite, T;

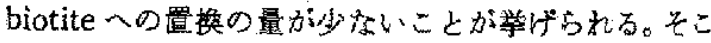
で，置換の量是专礼でれ2，4倍して，

$$
\begin{aligned}
& \text { Eastonite } \cdots \cdots \cdots \cdots \cdot \mathrm{K}_{2} \mathrm{R}^{2+}{ }_{4} \mathrm{Al}_{2} \mathrm{Si}_{4} \mathrm{Al}_{4} \mathrm{O}_{20}(\mathrm{OH})_{4} \\
& \text { Ti-biotite } \cdots \cdots \cdots \cdots \cdot \mathrm{K}_{2} \mathrm{R}^{2+}{ }_{4} \mathrm{Ti}_{2} \mathrm{Si}_{2} \mathrm{Al}_{6} \mathrm{O}_{20}(\mathrm{OH})_{4}
\end{aligned}
$$

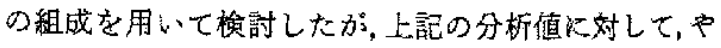
性り一部の黒雲和は eastonite 成分が負の值をるつ。

このことは, 領家変成岩中のいくつかの黑雲母方，彼 らの定めたTiに蒚多得る黒雲母炕よって定掌された 組成空間の外にあることを意味する。そこで請査地域 の黑雲拇中のTiの增加に相関をるつ元素学求的，結

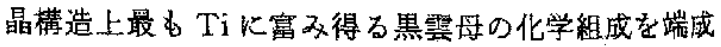
分とする检討を行なった。 


\section{Ti 黑需母端成分}

Fig. 1 飞示される Ti 変動のらち, 特に広い変動の見 られる陚料(YCH3)は，董青石带の譺質岩中の黑雲母 で, $0=22$ とした時にTi含有量は 0.16 から 0.52 京

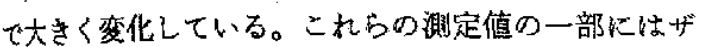
ク砛の包有物，あるいはザク口石を置換した脈状の 黑需母含むれが，多くはマトリクスの黑雲母であ る。そして，椂辺部に向かって $\mathrm{Mn} の$ 增加する，逆累 带構造示すザクロ石に向かって，黒雲母の Ti含有 量汃减少する。その成因については别に詳しく議論す るが,この一枚の薄片中の黑雲母の測定值を用いて Ti

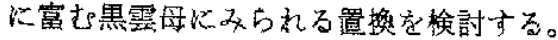

黒雲母の結晶構造のサイトごと纫 Ti 之相関をわっ 元素を検討する。Fig. 2 にTの变動に対して，各元素 の量を示した。この図からかかる上らにTiの変動以

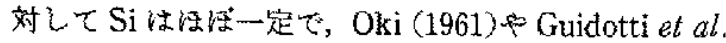
(1977)の指墑した，負の相壁はみられない。Aサイト に入る元素である $\mathrm{K}, \mathrm{Ca}, \mathrm{Na}$ の総和恼はらつくが, Ti の変動とは明瞭な相関をもたない。 $\mathrm{MnO}$ は $0.25 \mathrm{wt} \%$

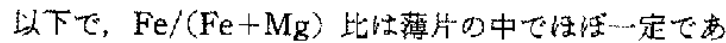
る。更に, $\mathrm{Fe}, \mathrm{Mg}, \mathrm{Mn}$ の総和 $\left(=\mathrm{R}^{2+}\right)$ 上 Ti の変動

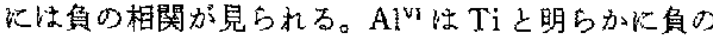

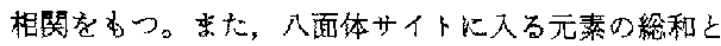

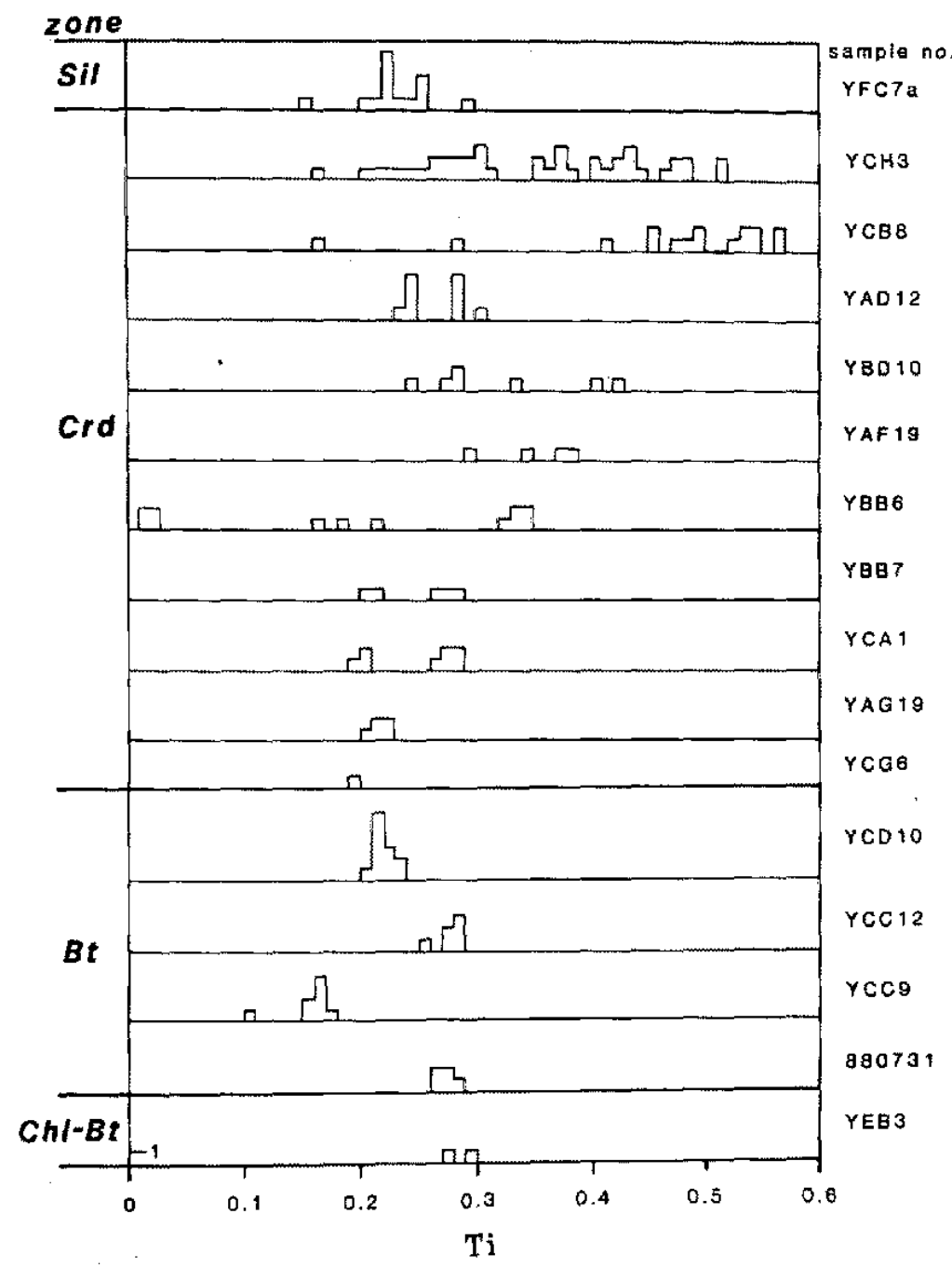

Fig.1. Ti content of biotite from pelitic and siliceous rocks in the Yanai district of the Ryoke metamorphic belt, based on 22 oxygens. Abbreviations: Chl-Bt, chlorite-biotite zone; $\mathrm{Bt}$, biotite zone; Crd, cordierite zone; Sil, sillimanite zone. 

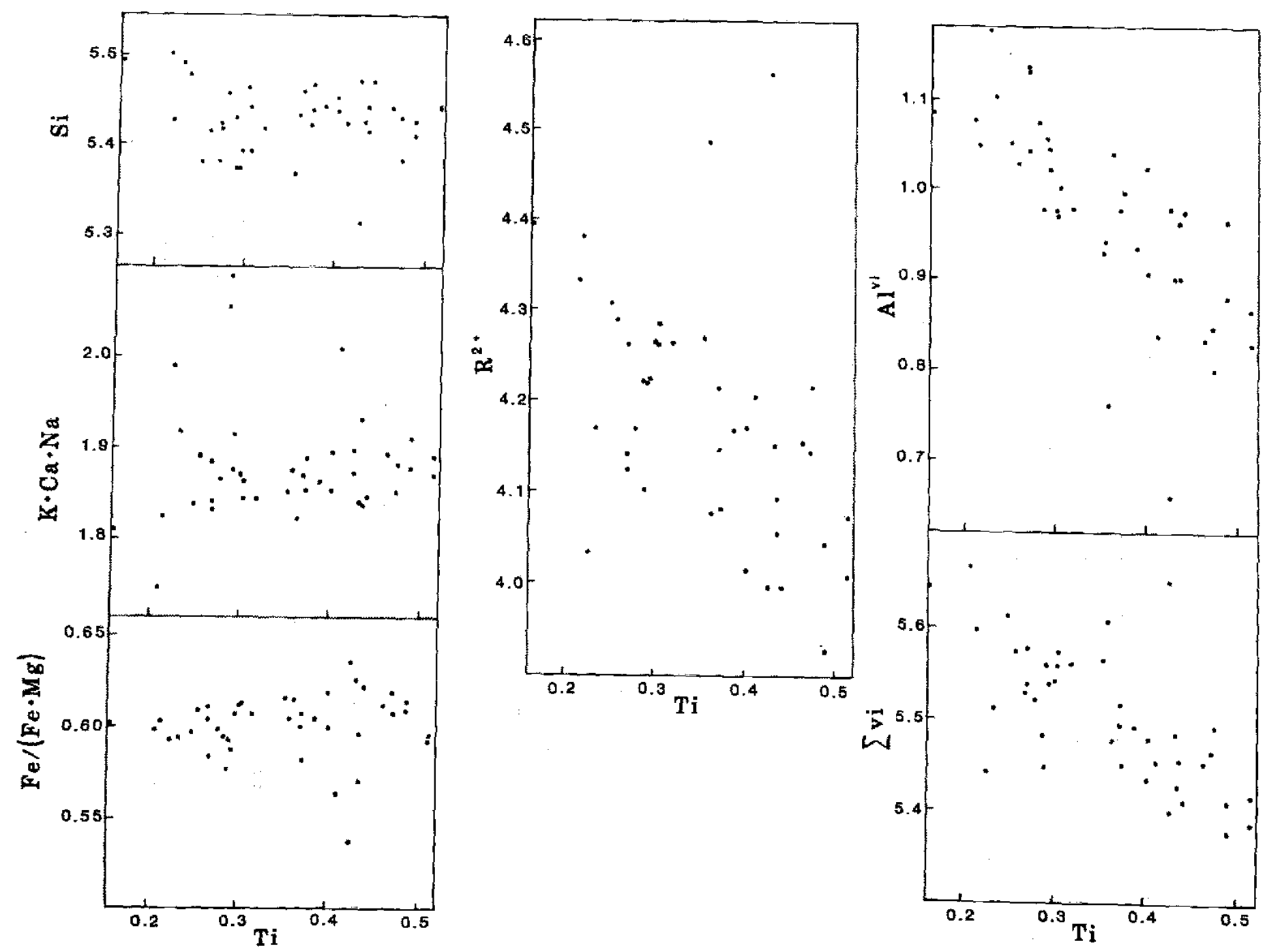
Fig. 2. Plot of each element vs. Ti per 22 -oxygen formula unit for biotite from one thin section in the cordierite zone (sample no. YCH3).
Note that $A 1^{v}=S i+A i-8$. 
Table 1. Calculation of endmember properties for representative analyses of biotite from the study area

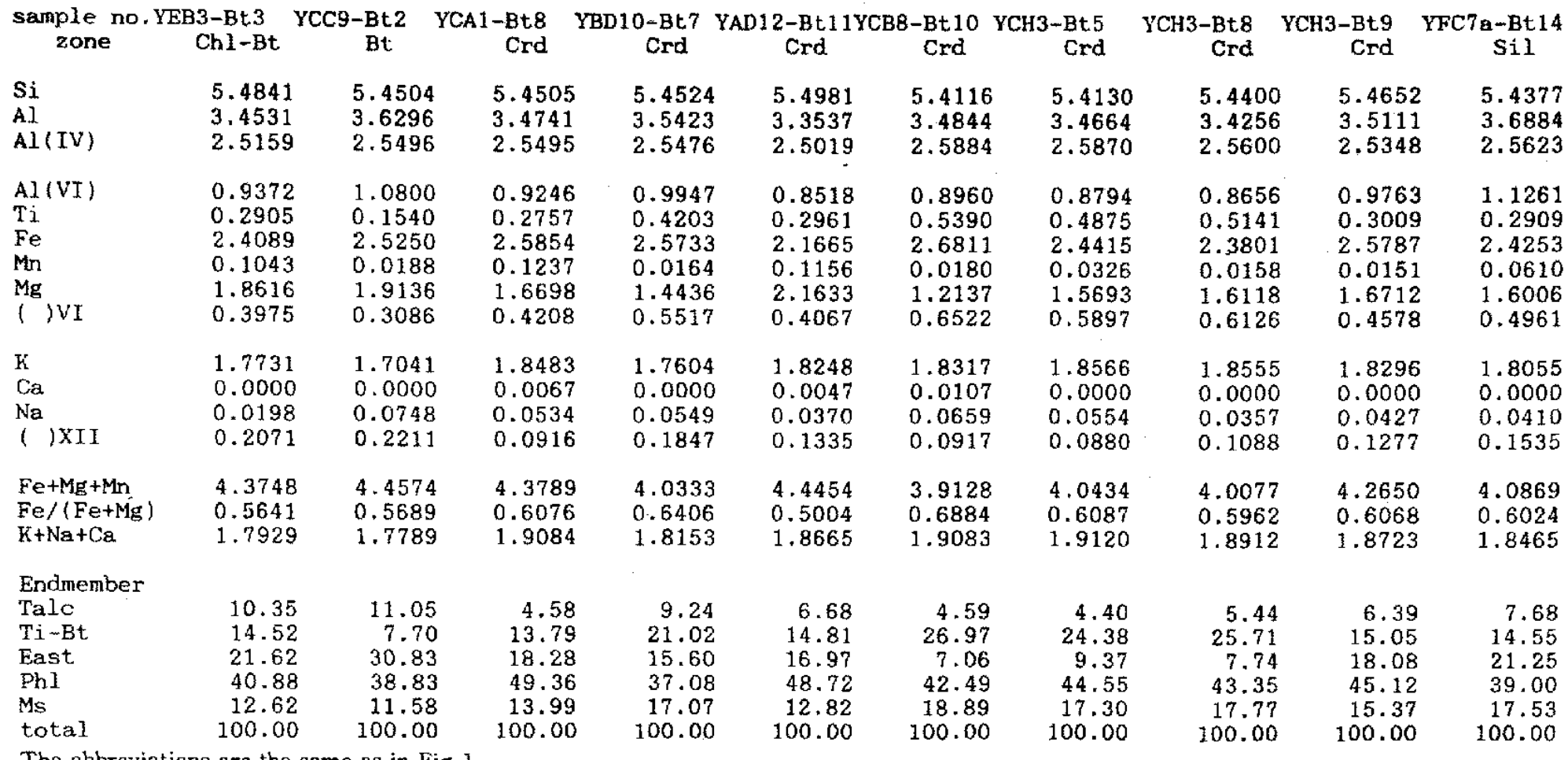


Tiにも負の相関がみられる。これはTiの犆換に八面 体サイトの空席が関与していることを示唆する。

Ti比対する $\mathrm{R}^{2+}$ の負の相開，八面体サイトの空席の 関与は Holdaway et al. (1988) の置換で説明できる

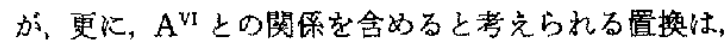
電価のバランス教隐する之次の上うになる。

$$
2 \mathrm{Ti}+\mathrm{D}^{\mathrm{VI}}=2 \mathrm{Al} \mathrm{I}^{\mathrm{vi}}+\mathrm{R}^{2+}
$$

この置换は従来から指摘されている3 つの置撸を合 成したるのに一致する。即ち，

$$
\begin{aligned}
& \left.\mathrm{Ti}_{2} \square\right]^{\mathrm{V}} \mathrm{R}^{2+}{ }_{-1} \mathrm{Al}^{\mathrm{VI}}-2= \\
& \mathrm{Ti} \square^{\mathrm{VI}} \mathrm{R}^{2+}{ }_{-2}^{+} \\
& \mathrm{TiAl}^{\mathrm{IV}} \mathrm{R}^{2+}{ }_{-1} \mathrm{Si}_{-2}+ \\
& \mathrm{R}^{2+}{ }_{2} \mathrm{Si}_{2} \mathrm{Al}^{\mathrm{VI}}{ }_{-2} \mathrm{Al}^{\mathrm{vv}}{ }_{\cdots 2}
\end{aligned}
$$

(Holdaway et al., 1988)

(Oki, 1961)

(Tschermak 置換)

(1) 式

となる。ここで置換の淩記法妒 Thompson (1982) に 従った。つ专り，領家变成岩類の黒雲母のTi汇関する 置換を説的するためには Oki (1961) と Holdaway et al. (1988)の2つの Ti-biotite 端成分を考去なければ いけない:Oki (1961) の Ti-biotite $(=\mathrm{Ok})$ \& Holdaway et al. (1988) の Ti-biotite (=Hd). の間には,

$\mathrm{Ok}+$ Phlogopite + Muscovite $=\mathrm{Hd}+2$ Eastonite

の関係が成り立つので，いずれかを端成分としてむ，2 つとも端成分としてる，それ惴成分のとり方として 蜪されるが，実用的には端成分の数は少ない方が上 い。Ti红関して，(1) 式の左辺の置奥のみを用いて端 成分とするとTik対して1つの端成分方対応し，少 ない数の端成分を用いて皿雲母の化学組成を表玩でき

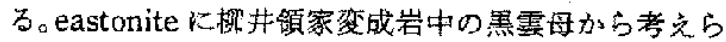
れたこの鲞換充施した組成，つ李り

$$
\mathrm{K}_{2}[] \mathrm{R}^{2+}{ }_{9} \mathrm{Ti}_{2} \mathrm{Si}_{4} \mathrm{Al}_{4} \mathrm{O}_{2 \mathrm{a}}(\mathrm{OH})_{4}
$$

老端成分之する之1つの端成分でTi含有量を报之 る。この組成は phlogopiteからは $\mathrm{Ti}_{2} \square{ }^{\mathrm{vI}} \mathrm{Al}^{\mathrm{IV}}{ }_{2} \mathrm{R}^{2+}$ $\mathrm{Si}_{-2}$ の置換を施した縕成である。

従って, Holdaway et al. (1988)の提案した端成分 のらち，Ti-biotiteのみを上記の組成に置き換えた 5

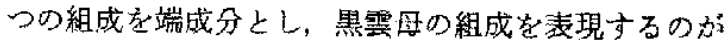
適当である考克られる。各端成分の量比の訪算は, A サイトの空席孝 talc とし，Ti てること以外性 Oki (1961)の手法に狚った。この方法 では， $\mathrm{Ti}^{\mathrm{jv}}$ 除くと端成分量比性計算順序に依らな い。謂查地域の黑雲母の分析值 159 個のうち，この端 成分（=Ik）を用いた空間で 4 個は muscovite 成分が
負上なるが，それ以外性全ての成分が正の值と儿て表 現される。代表的な分析值についての計算を Table 1 に示す。Holdaway et al，(1988) の端成分（=Hd）て は筆者の分析䛧のうら，7㑭方 muscovite 成分方負に なる。Oki (1961) の eastonite, Ti-biotite にっいての

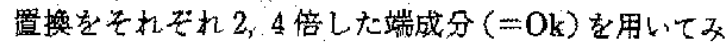
ると同じデータについて39個が負の eastonite 成分 を，3個が負の muscovite 成分をむつ。

t, Holdaway et al. (1988) の Maine 地域o 40 個のデータ学現すると, lkではI個が、Hdでは?個 が muscovite 成分が負になり，Okでは 3 個が，負の eastonite 成分老もつ。更k, Guidotti et al. (1975, 1977)の Maine 地域の 37 個のデータ は Ik で全て正の

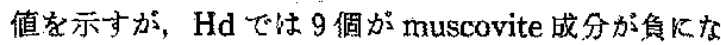
り，Okでは 4 堌が eastonite 成分が負になる。即ち，こ れらの黒需母の組成を最す適切に表現し得る空間蚛今 回提案したTi-biotite 端成分とする空間である。

更k, Schreyer et al. (1980) 肪天然の試料为ら,

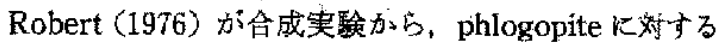
$\mathrm{Ti}$ の溶解度が低いことを指摘している。このことか

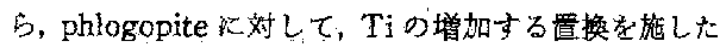
Oki (1961), Dymek (1983), Holdaway et al. (1988) の提案した Ti-biotite 端成分の組成俚，実在す西組成 でない可能性がある。但 L, Whitney and McLelland （1983）は Adirondack 地域の変成ガブロから $\mathrm{Ti}$ 含有 量の高い phlogopiteを記載しているが，で中で

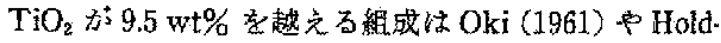
away et al. (1988) の端成分系では，muscovite 成分 が，25\% す真の值となるのに対し，今回の端成分系で

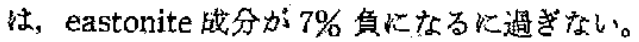

以上のことから，Ti 含喜雲母の組成を適切飞表 現でき端成分として，今回提案した組成は奖当であ る上考克られる。

謝辞本研究を進めるにあたり，京都大学理学 部地質学鍍物学教空, 坂野留平教授には, 終始討論し て頂いた。弘前大学理学部地球科学教室, 柴正敏講師,

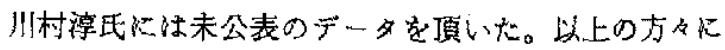
心から感謝する。

\section{文献}

Dymek, R.F. (1983), Titanium, aluminum and interlayer cation substitutions in biotite from highgrade gneisses, West Greenland. Amer. Mineral., $68,880-899$. 
Farmer, G.L. and Boettcher, A.L. (1981), Petrologic and crystal-chemical significance of some deep-seated phlogopites. Amer. Mineral, 66, $1154-1163$.

Guidotti, C.V. (1984), Micas in metamorphic rocks. Rev. Mineral, Mineral. Soc. Amer., 13, 357-468.

Guidotti, C.V., Cheney, J.T. and Conatore, P.D. (1975), Interrelationship between $\mathrm{Mg} / \mathrm{Fe}$ ratio and octahedral Al content in biotite. Amer. Mineral, 60, 849-853.

Guidotti, C.V., Cheney, J.T and Guggerheim, S. (1977), Distribution of titanium between coexisting muscovite and biotite in pelitic schists from northwestern Maine. Amer. Mineral.; 62, $438-448$.

Holdaway, M.J., Dutrow, B.L. and Hinton, R.W. (1988), Devonian and Carboniferous metamorphism in west-central Maine: The muscovitealmandine geobarometer and the staurolite problem revisited. Amer. Mineral., 73, 20-47.

Oki, Y. (1961), Biotites in metamorphic rocks. Jajan, J. Geol. Geograp., 32, 497-506.
Pattison, D.R. (1987), Variations in $\mathrm{Mg} / \mathrm{Mg}+\mathrm{Fe}$ ), $\mathrm{F}$ and $(\mathrm{Fe}, \mathrm{Mg}) \mathrm{Si}=2 \mathrm{Al}$ in pelitic minerals in the Ballachulish thermal aureole, Scotland. Amer. Mineral, 72, 255-272.

Robert, J.L. (1976), Titanium solubility in synthetic phlogopite solid solutions. Chem. Geol, 17, 213-227.

Schreyer, W., Abraham, K. and Kulke, H. (1980), Natural sodium phlogopite coexisting with potassium phlogopite and sodian aluminian talc in metamorphic evaporite sequence from Derrag, Tell Atlas, Algeria. Contrib. Mineral. Petrol., 74, 223-233.

Thompson, J.B. (1982), Composition space: An algebraic and geometric approach. Rev. Min. eral, Mineral. Soc. Amer, 10, 1-32.

Whitney, P.R. and McLelland, J.M. (1983), Origin of biotite-homblende-gamet coronas between oxides and plagioclase in olivine metagabbros, Adirondack region, New York. Contrib. Mineral. Petrol., 82, 34-41. 